\title{
Virtual cognitive stimulation therapy: perspectives of people living with dementia
}

\author{
Terapia de estimulação cognitiva virtual: \\ Perspectivas de pessoas vivendo com demência
}

\author{
Michael Lepore ${ }^{\mathrm{a}}\left(\mathbb{0}\right.$, Stephani Shivers ${ }^{\mathrm{b}}$, Erica DeFrancesco ${ }^{\mathrm{a}}$
}

Cognitive Stimulation Therapy (CST) is a group treatment in which people with mild to moderate dementia participate in 14 activity and discussion sessions. During the COVID-19 pandemic, CST was adapted for online delivery, as virtual-CST (V-CST). To determine the acceptability of online delivery, we piloted a V-CST group, monitored attendance, and assessed qualitative feedback from the participants. Five people with dementia participated. Except for one session with four attendees, all participants attended every session. Qualitative analysis identified four themes that were verified by participants: (1) positive emotional experiences despite dementia, (2) confidence building and related strategies and challenges, (3) enjoyable and stimulating inclusive activities and group dynamics, and (4) appreciation of discussion about current affairs. This pilot study contributes evidence about the acceptability of V-CST. Although access to CST in the United States is limited, expanded delivery of V-CST could fill service gaps.

KEYWORDS: group therapy; internet-based intervention; adaptation.

A terapia de estimulação cognitiva (CST) é um tratamento em grupo no qual pessoas com demência leve a moderada participam de 14 atividades e sessões de discussão. Durante a pandemia de COVID-19, a CST foi adaptada para entrega online, como CST virtual (V-CST). Para determinar a aceitabilidade da entrega online, testamos a V-CST, monitoramos a frequência, e os participantes deram feedback qualitativo. Participaram cinco pessoas com demência. Exceto por uma sessão com quatro participantes, todos os participantes compareceram a todas as sessões. A análise qualitativa identificou quatro temas que foram verificados pelos participantes: (1) experiências emocionais positivas apesar da demência, (2) construção de confiança e estratégias e desafios relacionados, (3) atividades inclusivas agradáveis e estimulantes e dinâmica de grupo e (4) apreciação da discussão sobre assuntos atuais. Este estudo piloto contribui com evidências sobre a aceitabilidade da V-CST. Embora o acesso à CST nos Estados Unidos seja limitado, a oferta expandida da V-CST pode preencher lacunas desse serviço.

PALAVRAS-CHAVE: terapia de grupo; intervenção via internet; adaptação.

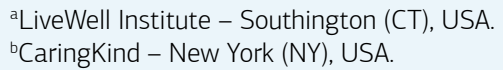

Correspondence data

Michael Lepore - LiveWell Institute, 1261 - South Main - St. Plantsville - CT 06479 - United States. E-mail: mlepore@livewell.org Received on: 07/15/2021. Accepted on: 09/08/2021.

How to cite this article: Lepore M, Shivers S, DeFrancesco E. Virtual cognitive stimulation therapy: perspectives of people living with dementia. Geriatr Gerontol Aging. 2021;15:e0210042. https://doi.org/10.53886/gga.e0210042

https://doi.org/10.53886/gga.e0210042 


\section{INTRODUCTION}

Cognitive Stimulation Therapy (CST) is an evidence-based group therapy intervention for people with mild to moderate dementia that, over the course of 14 sessions, offers engagement in activities and discussions. ${ }^{1}$ Randomized control trials indicate that CST has a beneficial impact on participant quality of life, ${ }^{2}$ depression, ${ }^{3}$ and cognition. ${ }^{4}$ Cost-effectiveness analysis has shown that CST is cost effective and has benefits comparable to pharmacological treatment. ${ }^{5}$ Since 2006, CST has been recommended by the United Kingdom's National Institute for Health and Care Excellence. ${ }^{6,7}$

During the COVID-19 pandemic, CST trainers in New Zealand shifted CST to online delivery, known as virtual-CST (V-CST). ${ }^{8}$ Interested in filling treatment gaps for people with dementia in the United States, ${ }^{9}$ especially treatments that permit social distancing, members of our team (ML, SS) met with CST trainers in New Zealand to learn about their experiences with $\mathrm{V}$-CST.We learned of technological barriers to participation and applied lessons such as requiring V-CST participants live with a supporter (e.g., family member) who can assist with technology issues.

Through piloting V-CST, we sought to make CST available to people with dementia in Connecticut and to understand its acceptability. We did this by monitoring attendance and receiving participant feedback about each session and after the full course of treatment.

\section{METHODS}

Using Zoom, the V-CST pilot group launched in November 2020 and concluded in January 2021. A convenience sample of five people with dementia participated. The number was capped at five, consistent with the recommended size of V-CST groups. ${ }^{8}$ All sessions lasted approximately one hour and had the same primary interventionist (ED). Attendance was noted at each session. Before the first session, the participants were offered the option of completing the St Louis University Mental Status (SLUMS) to assess their level of cognitive impairment.

After each session, the primary interventionist emailed participants requesting feedback on the session, including what they considered the best and worst parts and changes they would recommend. After the final session, the questionnaire also asked about improvements experienced and challenges faced during V-CST. Iterative thematic inquiry was used to analyze participant feedback. ${ }^{10}$ Participant responses were collated weekly and read by three team members (ED, SS, ML). Toward the end of treatment, but before the final session (S14), initial themes ("Positive Emotional Experience", "Self-Mastery", "Group Dynamics", and "Appreciation of Current Affairs Discussion") were generated to characterize participant feedback.
After completing all 14 sessions, we conducted longitudinal iterative thematic inquiry by comparing statements on each theme over the course of treatment. Participant responses were read line by line and compared with each other to assess changes over time, as well as with the initial themes. The initial themes were revised to reflect the full set of responses. For example, the initial theme "Self-Mastery" was changed to "Self-Esteem and Related Challenges", for two reasons. First, "Self-Esteem", meaning a sense of self-worth, was determined to better reflect participant views than "Self-Mastery", meaning a sense of personal control based on the belief that one's actions will produce desired ends. Second, "Related Challenges" was added to encompass other difficulties that participants reported facing in the sessions. The participants were invited to review the themes. Three completed the review. All three verified the findings.

\section{RESULTS}

The pilot study group included three White women and two White men (Table 1). Except for one session with four attendees, all five participants attended every session. Participant scores on the SLUMS indicate that three had dementia (scores between 0 and 20) and one had mild cognitive impairment (scores between 21 and 26). One participant declined to complete the SLUMS.

\section{Participant feedback}

Participant feedback about V-CST was consistently positive. No thematic changes occurred over the course of treatment. From the first session (S1) to the fourteenth session (S14), positive feedback was provided, like "Thought it went well" (S2); "Another good session, no recommended changes"(S7); "Session was great" (S9); "As always, the overall session was great" (S11); and "Thanks for leading these sessions. They were most enjoyable" (S13). In addition to the positive feedback, participant responses evoked four themes: (1) positive emotional experiences despite dementia,(2) confidence-building and related strategies and challenges, (3) enjoyable and stimulating inclusive activities and group dynamics, and (4) appreciation of current affairs discussions. These themes, observed over the course of V-CST, are summarized with representative quotes below and in Figure 1.

\section{Positive emotional experiences despite dementia}

Although difficulty remembering sessions was commonly reported, participants more commonly reported enjoying participation in V-CST, and this persisted over the course of treatment (Figure 1). For example, toward the beginning of treatment, one participant reported, "I remember nothing specific about the meeting. I liked the experience and the 
opportunity to talk with other people"(S2). Similarly, toward the end of treatment, another participant reported, "My memory keeps me from making specific comments or suggestions, but I like spending the time with the group" (S10).

\section{Self-esteem and related challenges}

The participants emphasized feeling good about themselves and getting a self-esteem boost from V-CST (Figure 1). For example, after a session with word games, one participant favorably described its effects on personal cognitive capacity: "I had not played in years and it reminded me that I can still figure out things" (S13). Challenges also were identified, including activities that were too difficult, and problems with vision and hearing. For example, in a session focused on numbers, one participant commented about cognitive and visual difficulties (Figure 1). Hearing issues and sound quality also can be a problem, since a participant who otherwise enjoyed a sound-focused exercise disliked the sound itself: "I have a particular issue that the sound itself was abrasive" (S2).
Inclusive, enjoyable, and stimulating activities and interactions

Participant feedback consistently emphasized enjoying the inclusiveness of $\mathrm{V}-\mathrm{CST}$ and being stimulated by interacting with the group and participating in group activities (Figure 1). The inclusiveness of V-CST was appreciated by participants who shared comments like "everyone was asked for ideas to make this a special group. Each person was asked questions. So we were all a part of the day" (S1). What one participant liked best was "the continuing congeniality of the group and the opportunity to speak in a safe/comfortable environment"(S12). V-CST also was consistently depicted as stimulating participant memory and thinking. As one participant succinctly explained: "Good discussion; provoked thinking of prior experiences"(S11).

\section{Appreciation of current affairs discussions}

The participants consistently reported appreciating discussions on current affairs in V-CST, especially those of potentially provocative topics (Figure 1). After several sessions, the participants reported that what they liked best was the current

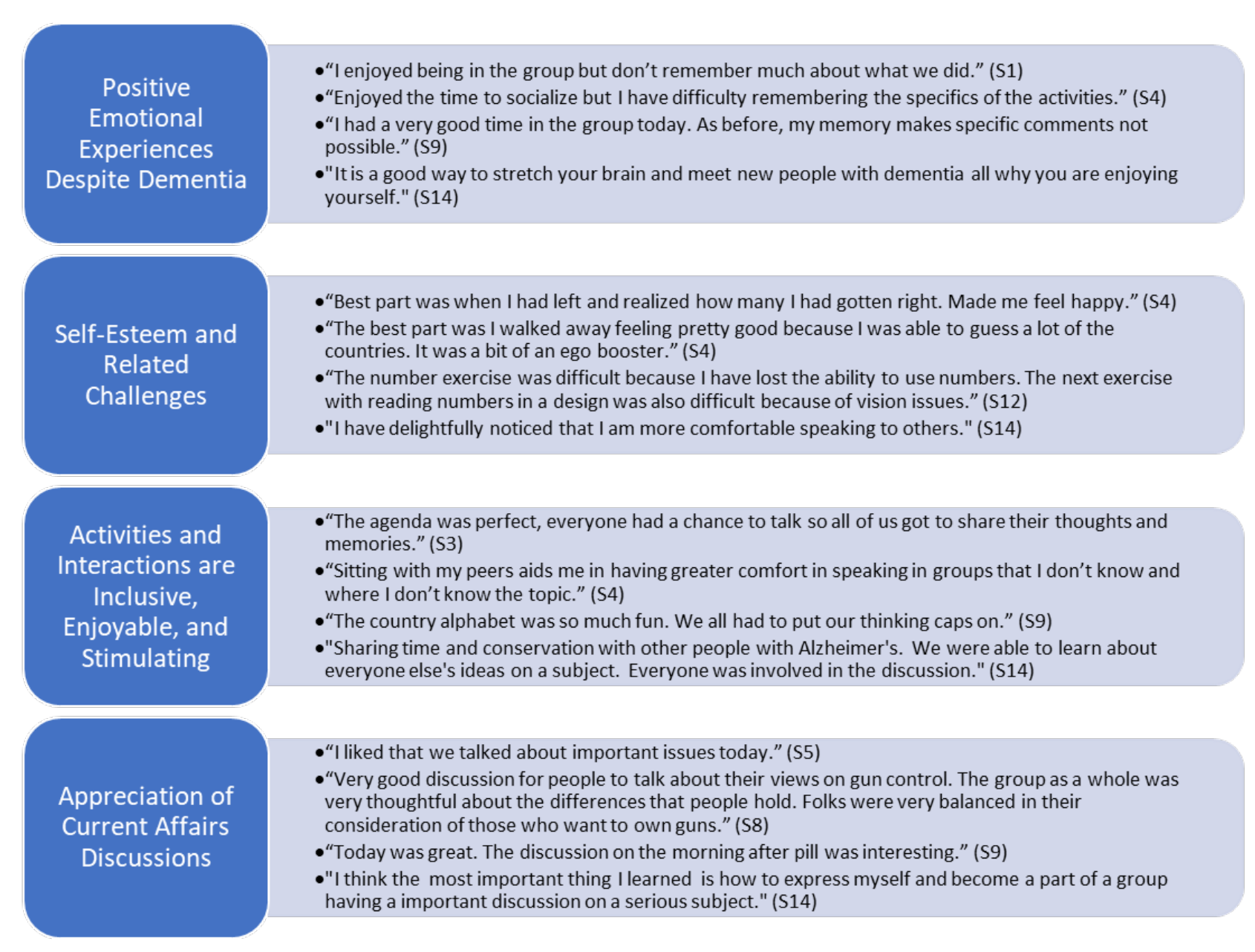

Figure 1. Themes and representative quotes. 
affairs discussion. For example: "Discussion of gay marriage, a topic that really brings people out. I was using my speaking skills and also needed to focus on thinking through the topic" (S5), "The best part was the gun control discussion" (S8), and "Discussion about the morning after pill was the best"(S9).

\section{DISCUSSION}

Building on the evidence that CST improves outcomes like cognition among people with dementia, this pilot study contributes evidence that online delivery is acceptable and feasible in practice. V-CST meets a need for people with dementia to maintain access to evidence-based treatments in contexts when gathering in person is nonviable, such as during the pandemic or when transportation options are limited.

In this pilot study, five people with mild to moderate dementia participated in V-CST. No participants dropped out of the V-CST group and attendance was nearly perfect, with only one participant missing just one of fourteen sessions. From the first to the fourteenth session, the participants provided positive feedback about their experiences. The participants emphasized having positive emotional experiences despite dementia, building confidence, especially in communication skills, enjoying the V-CST activities and group dynamics, and appreciating the discussions on current affairs.

\section{CONCLUSION}

Future research needs are identified. This pilot V-CST group included five people with dementia, all of whom were White. Future testing of V-CST is needed with larger and more diverse groups. Whereas the pilot V-CST group consistently reported enjoying the discussions of potentially provocative current affairs like gay marriage and birth control, for example, responses to such topics in groups with more diverse participants also must be examined.

\section{ACKNOWLEDGEMENTS}

The authors wish to thank the individual V-CST participants, who generously committed time to providing informative feedback after participating in the sessions and who reviewed this manuscript and verified the study findings.

\section{CONFLICTS OF INTEREST}

The authors declare no conflicts of interest.

\section{FUNDING}

This work was partially supported by a grant from the Bradley Henry Barnes \& Leila Upson Barnes Memorial Trust at the Main Street Community Foundation.

\section{AUTHORS' CONTRIBUTION}

ML: conceptualization, formal analysis, investigation, methodology, project administration, supervision, validation, writing - original draft. SS: conceptualization, funding acquisition, methodology, project administration, supervision. ED: data curation, formal analysis, investigation, methodology, validation, writing - review \& editing.

\section{REFERENCES}

1. Spector A, Thorgrimsen L, Woods BO, Royan L, Davies S, Butterworth $M$, et al. Efficacy of an evidence-based cognitive stimulation therapy programme for people with dementia: randomised controlled trial. $\mathrm{Br}$ j Psychiatry. 2003;183(3):248-54. https://doi.org/10.1192/ bjp.183.3.248

2. Butler M, Gaugler JE, Talley KM, Abdi HI, Desai PJ, Duval S, et al. Care interventions for people living with dementia and their caregivers. Comparative Effectiveness Review No. 231 (Prepared by the Minnesota Evidence-based Practice Center under Contract No.290-2015-00008-I.) AHRQ Publication No. 20-EHC023. Rockville, MD: Agency for Healthcare Research and Quality; 2020.

3. Stewart DB, Berg-Weger M, Tebb S, Sakamoto M, Roselle K, Downing L, et al. Making a difference: A study of cognitive stimulation therapy for persons with dementia. J Gerontol Soc Work. 2017;60(4):300-12. https://doi.org/10.1080/01634372.20 17.1318196

4. Aguirre E, Hoare Z, Streater A, Spector A, Woods B, Hoe J, et al. Cognitive stimulation therapy (CST) for people with dementia who benefits most? Int J Geriatr Psychiatry. 2013;28(3):284-90. https://doi.org/10.1002/gps.3823
5. Knapp M, Thorgrimsen L, Patel A, Spector A, Hallam A, Woods B, Orrell M. Cognitive stimulation therapy for people with dementia: cost-effectiveness analysis. Br J Psychiatry. 2006;188(6):574-80. https://doi.org/10.1192/bjp.bp.105.010561

6. National Institute for Health and Care Excellence. Dementia: supporting people with dementia and their carers in health and social care. Available from: https://www.nice.org.uk/guidance/cg42. Accessed in Nov 25, 2020.

7. National Institute for Health and Care Excellence. Dementia: assessment, management and support for people living with dementia and their carers. Available from: https://www.nice.org. uk/guidance/ng97. Accessed in Oct 25, 2021.

8. Cheung G, Peri K. Challenges to dementia care during COVID-19: innovations in remote delivery of group cognitive stimulation therapy. Aging Ment Health. 2021;25(6):977-9. https://doi.org/10.1080/13607863.2020.1789945

9. Gitlin LN, Baier RR, Jutkowitz E, Baker ZG, Gustavson AM, Sefcik JS, et al. Dissemination and implementation of evidence-based dementia care using embedded pragmatic trials. J Am Geriatr Soc. 2020;68 Suppl 2(Suppl 2):S28-S36. https://doi.org/10.1111/jgs.16622

10. Morgan DL, Nica A. Iterative thematic inquiry: a new method for analyzing qualitative data. Int J Qual. 2020;19:1609406920955118. https://doi.org/10.1177/1609406920955118 